\title{
Influence of Acid-Base Alterations on Myocardial Sensitivity to Catecholamines
}

\author{
María Cristina Camilión de Hurtado*, María Isabel Argel**, and Horacio Eugenio Cingolani* \\ Centro de Investigaciones Cardiovasculares, Facultad de Ciencias Médicas, Universidad Nacional de la Plata, 60 y 120 (1900), La Plata, Argentina
}

\begin{abstract}
Summary. The influence of "respiratory" and "metabolic" acid-base alterations on the myocardial sensitivity to catecholamines was studied in the isolated rat atria. The ability of noradrenaline for increasing the atrial rate was enhanced during alkalosis and conversely, it was decreased by acidosis. These changes in sensitivity shifted the concentration-effect curve for noradrenaline to the right by about $0.5 \log$ unit when the $\mathrm{pH}$ was lowered from 7.60 to 7.00 . No changes in the maximum attainable response were detected. Essentially the same shifts of the concentration-effect curves were obtained with changes in $\mathrm{pH}$ brought about by altering the $p \mathrm{CO}_{2}$ or at constant $p \mathrm{CO}_{2}$. The decrease in the $\mathrm{pH}$ produced a similar shift to the right of the concentration-effect curve for isoprenaline, after the extraneuronal uptake inhibition by hydrocortisone and also in atria tissue with low content of endogenous noradrenaline (reserpine-pretreated and newborn rats). The ability of isoprenaline for increasing cyclic AMP levels in atrial tissue was also enhanced by alkalosis and decreased by acidosis. However, the shift to the right of the concentration-effect curve for cyclic AMP induced by the decrease in the $\mathrm{pH}$ was greater than the shift detected in the chronotropic-effect curve. In addition a decrease in the maximum increment of cyclic AMP was detected under acidosis, in spite of equal maximal chronotropic response.

Our results support the hypothesis that the alterations in the sensitivity to catecholamines induced by the changes in $\mathrm{pH}$ are not due to a release of endogenous noradrenaline nor to alterations of the mechanisms which remove catecholamines from the biophase. The fact that cyclic AMP response to catecholamines was also reduced by acidosis strongly suggests that the mechanism(s) involved is located in the earlier steps of the events leading to the chronotropic effect of the $\beta$-agonists.
\end{abstract}

Key words: Acid-base alterations - Cyclic AMP - Atrial rate - Catecholamines

\section{Introduction}

The influence of acid-base alterations on the cardiovascular response to catecholamines has been studied by several investigators (Bendixen et al. 1963; Burgett and Visscher 1927; Collip 1921; Nahas and Poyart 1967; Page and

Send offprint requests to $\mathrm{H}$. E. Cingolani to the above address

* Members of the Carrera del Investigador, Consejo Nacional de Investigaciones Científicas y Técnicas, Argentina

** Member of the Carrera del Investigador, Comision de Investigaciones Científicas de la Provincia de Buenos Aires, Argentina
Olmstead 1951; Salant and Johnston 1924). However, considerable controversy has surrounded about the effect of acidbase disturbances on catecholamine actions. Several authors found that the myocardial and vascular responses to adrenaline were reduced during acidosis (Collip 1921; Darby et al. 1960; Manley et al. 1966; Schroeder et al. 1970), whereas in other studies only hypercapnic acidosis showed a depressant effect on catecholamine actions (Burgett and Visscher 1927; Page and Olmstead 1951). Bendixen et al. (1963) reported that the effect of adrenaline on myocardial contractile force was decreased when decreasing $\mathrm{pH}$, but no correlation was found between $\mathrm{pH}$ and the vascular and chronotropic effects of adrenaline, suggesting that the effect of $\mathrm{pH}$ on catecholamine actions might change with the type of response involved. Furthermore, there have been conflicting reports as to whether the depressant effect of acidosis on catecholamine response is a direct action of the increased $\mathrm{H}^{+}$activity, a consequence of hemodynamic changes (Downing et al. 1965) or due to the increased circulating levels of endogenous catecholamines (Tenney 1956).

Experiments were undertaken in an attempt to answer the following questions: (1) Are the effects of acid-base alteration on the chronotropic response to catecholamines due to changes in $\mathrm{pH}$ or related to changes in $p \mathrm{CO}_{2}$ ?. (2) Are the effects of acid-base alterations on catecholamines response the result of changes in the effective concentration of the amines in the biophase without a real change in sensitivity? (3) Do acid-base alterations affect the increase in cyclic AMP production, as they change the chronotropic response?

\section{Material and Methods}

Spontaneously beating atria isolated from adult $(250-300 \mathrm{~g})$ and newborn rats (less than 6 days old) were used. Adult animals were anesthetized with sodium pentobarbitone $(8 \mathrm{mg} / \mathrm{kg}$ i.p. $)$ and the newborn ones with ether. The hearts were quickly excised and placed in an oxygenated saline solution. Both atria were dissected free and immediatly mounted in a $50-\mathrm{ml}$ bath containing a saline solution of the following composition (in millimoles per liter): $110 \mathrm{NaCl}$, $5 \mathrm{KCl}, 2.25 \mathrm{CaCl}_{2}, 1 \mathrm{MgSO}_{4}, 24 \mathrm{NaHCO}_{3}, 1 \mathrm{Na}_{2} \mathrm{PO}_{4} \mathrm{H}$, 0.045 EDTA, 0.11 ascorbic acid and 11 dextrose. One end of the atria was fixed to a Blinks type holder (1965) and the other was connected to a displacement transducer by means of stainless steel wire to record the spontaneous atrial contractions in a Sanborn 7712 Recorder. Before testing the drugs the preparations were washed several times and allowed to stabilize until the spontaneous rate did not change in more than 5 beats $\min ^{-1}$ during a $10-\min$ period. The stabilization period usually took $60 \mathrm{~min}$. All the experiments were carried out at $37^{\circ} \mathrm{C}$. 
Two groups of experiments were performed.In one group, concentration-effect curves for noradrenaline and isoprenaline at different extracellular $\mathrm{pHs}$ were determined. The changes in $\mathrm{pH}$ were obtained by two different procedures: in one of them (named "respiratory acid-base alterations") the $\mathrm{pH}$ of the medium was changed by gassing the solution with different gas mixtures: 3,5 and $13 \%$ of $\mathrm{CO}_{2}$ in $\mathrm{O}_{2}$ at a constant bicarbonate concentration $(24 \mathrm{mmol} / \mathrm{l})$. In the other experimental approach ("metabolic acid-base alterations") the changes in $\mathrm{pH}$ were obtained by setting the sodium bicarbonate concentration to 34 or $8 \mathrm{mmol} / 1$ at a constant $p \mathrm{CO}_{2}(37 \pm 1 \mathrm{~mm} \mathrm{Hg})$. In order to keep the $\mathrm{Na}^{+}$concentration and the osmolarity constant, the $\mathrm{NaCl}$ concentration in the saline solution was accordingly changed.

Solutions of $(-)$-noradrenaline bitartrate and $( \pm)$-isoprenaline $\mathrm{HCl}$ were prepared at $\mathrm{pH} 3$ and kept refrigerated until used. For each experiment appropriate dilutions were made with the saline solution.

Extraneuronal uptake was inhibited by addition of $28 \mu \mathrm{mol} / 1 \mathrm{hydrocortisone} 30 \mathrm{~min}$ before the response to isoprenaline was tested. Hydrocortisone was dissolved in ethanol and the solution was freshly prepared for each experiment. The final concentration of ethanol in the bath was $24 \mathrm{mmol} / 1$. No changes in basal atrial rate were detected when either ethanol or ethanol plus hydrocortisone were added.

In the experiments carried out with reserpine-pretreated rats, the animals were injected ( $5 \mathrm{mg}$ base $/ \mathrm{kg}$, i.p.) $24 \mathrm{~h}$ before the experiment.

The noradrenaline content in the atrial tissue of adult and newborn rats was measured by the method of Häggendal (1963).

Cumulative concentration-effect curves were determined by sequential addition of the catecholamine to the bath in amounts that increased the total concentration in steps of $1 \log$ unit to prevent the atria from long expositures to catecholamines in order to avoid deterioration of the preparations. Each concentration was allowed to act enough time to reach the maximum effect. The time interval between concentration changes varied from three to $4 \mathrm{~min}$, and $25-$ $30 \mathrm{~min}$ were required to complete a concentration-effect curve. When testing the response to noradrenaline, only one cumulative curve was determined in each preparation, whereas in the experiments with isoprenaline two successive curves were assayed since the results from preliminary experiments showed that two successive curves did not change the chronotropic response to isoprenaline. The response to catecholamines was expressed as the percentage of the maximum increase in rate attained in each experimental curve. $\log \mathrm{EC} 10,30,50,70$ and $90 \%$ were obtained by interpolation and the mean $( \pm$ SEM) of the log values were calculated at each effect level. The effect of changing the $\mathrm{pH}$ on catecholamine response was determined by measuring the horizontal shift between concentration-effect curves at the $50 \%$ effect level. Results were expressed as the mean ( \pm SEM) of the log shifts between curves. In the curves derived from unpaired experiments the shifts were measured by the differences between mean $\log \mathrm{EC}_{50}$ and the standard errors of the differences between means of unpaired samples were calculated.

The effect of the changes in $\mathrm{pH}$ on the intracellular cyclic AMP levels after catecholamine stimulation was studied in a second group of experiments. The isolated atria were stabilized during $60 \mathrm{~min}$ at three different values of extracellular
$\mathrm{pH}: 7.61,7.44$ or 7.01 . To change the $\mathrm{pH}$ of the media the same procedure as that described for "respiratory acid-base alterations" (see above) was followed. After the stabilization period a single concentration of isoprenaline, which ranged from $1 \times 10^{-10}$ to $1 \times 10^{-6} \mathrm{~mol} / \mathrm{l}$, was added to the bath. The atria were incubated for $3 \mathrm{~min}$ with isoprenaline and after recording the chronotropic response the tissue was quickly frozen in liquid $\mathrm{N}_{2}$. The tissues were pulverized into a fine powder and stored at $-70^{\circ} \mathrm{C}$ for subsequent measurements of cyclic AMP concentration. Basal cyclic AMP levels were determined from control experiments without addition of isoprenaline. Cyclic AMP content in the tissue was measured by the radio-immunoassay of Steiner et al. (1972) with acetylation of the samples as supplied by New England Nuclear (Harper and Brooker 1975).

Statistical significance of the results was determined by the Student's " $t$ " test. $P$ values $\leq 0.05$ were considered significant.

\section{Results}

The ability of noradrenaline to increase the spontaneous rate of isolated atria was changed during "respiratory" acidbase alterations. Concentration-effect curves for noradrenaline were determined at three different pHs: $7.65,7.44$ and 7.15 obtained by changing the $p \mathrm{CO}_{2}$. Noradrenaline was more potent in enhancing atrial rate at $\mathrm{pH} 7.65$ than at $\mathrm{pH} 7.44$ or 7.15. Conversely in acidosis noradrenaline was less potent in increasing spontaneous rate than at $\mathrm{pH} 7.44$. In order to emphasize the differences induced by changing hydrogen ion activity only the differences between the concentration-effect curves determined in alkalosis and acidosis were analyzed.

Figure 1 shows that the concentration-effect curve for noradrenaline was shifted to the right when hydrogen ion activity was increased. Thus larger concentrations of noradrenaline were required to elicit the same chronotropic effects, i.e. the concentration of noradrenaline required to produce half maximal increase in rate $\left(\log \mathrm{EC}_{50}\right)$ was -6.36 $\pm 0.11(n=12)$ at $\mathrm{pH} 7.15$ whereas the same effect was produced by a $\log \mathrm{EC}_{50}$ of $-6.88 \pm 0.15(n=14)$ at alkalotic pH $(P<0.05)$.

Basal atrial rate was slower in acidosis than in alkalosis. Spontaneous atrial rate was $154 \pm 11$ beats $\min ^{-1}(n=12)$ in acidosis and $202 \pm 11$ beats $\min ^{-1}(n=14)$ in alkalosis $(P<0.01)$. However the maximum increase in rate evoked by noradrenaline was similar at the two pHs $(171 \pm 11$ beats $\mathrm{min}^{-1}$ in alkalosis and $190 \pm 11$ beats $\mathrm{min}^{-1}$ in acidosis). No change in the maximum response was detected.

Similar results were obtained when the $\mathrm{pH}$ of the media was changed at constant $p \mathrm{CO}_{2}$. Figure 2 shows the concentration-effect curve for noradrenaline determined during "metabolic" alkalosis and acidosis. Increasing bicarbonate concentration from 24 to $34 \mathrm{mmol} / 1\left(p \mathrm{CO}_{2} 37 \pm 1 \mathrm{~mm} \mathrm{Hg}\right)$ increased the $\mathrm{pH}$ of the media from $7.44 \pm 0.01$ to $7.52 \pm 0.01$. The reduction of the bicarbonate concentration to $8 \mathrm{mmol} / 1$ lowered the $\mathrm{pH}$ to $7.03 \pm 0.01$. At $\mathrm{pH} 7.03$ the concentrationeffect curve for noradrenaline was shifted to the right of the curve determined at high bicarbonate concentration (pH 7.52) as it is shown in Fig. 2. In acidosis basal atrial rate was slower than in alkalosis, but the maximum increase in rate induced by noradrenaline was similar when the $\mathrm{pH}$ was altered.

The decrease in spontaneous atrial rate when increasing hydrogen ion activity has been previously reported (Camilión 

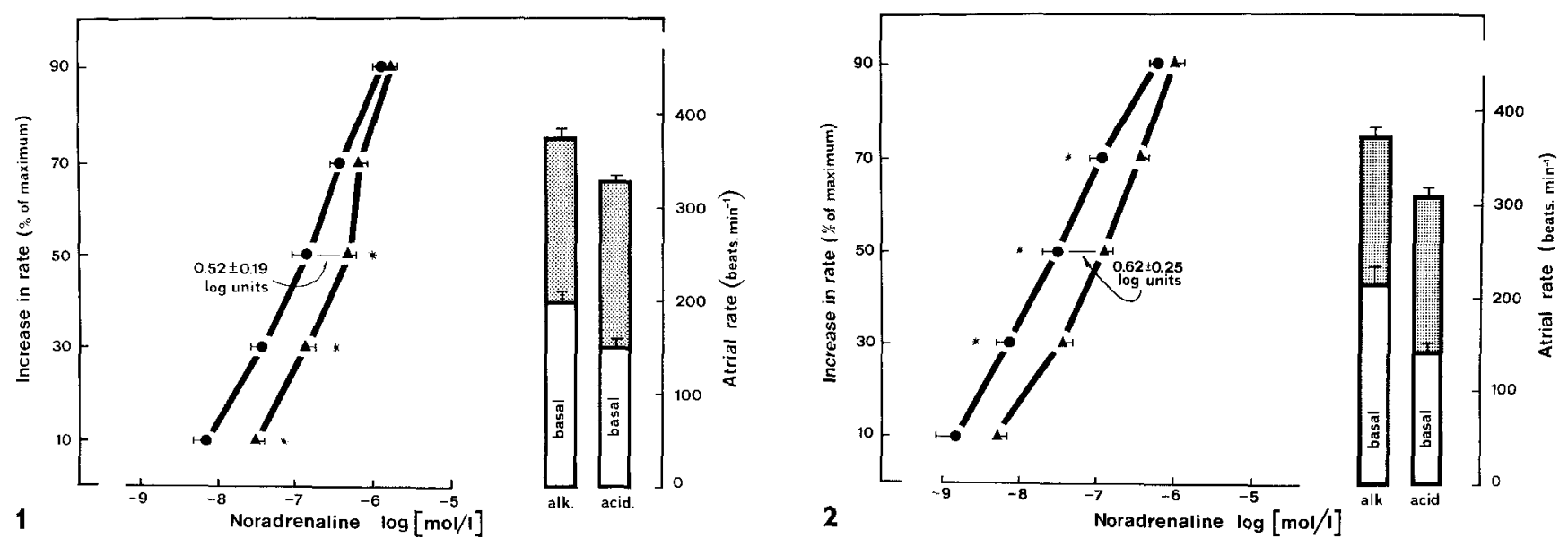

Fig. 1. Effect of "respiratory acid-base alterations" on the concentration-effect curves for the chronotropic action of noradrenaline in isolated rat atria. The chronotropic response was expressed as a percentage of the maximum increase in rate induced by noradrenaline. The logarithms of the concentrations associated with the 10,30,50,70 and $90 \%$ effect levels were calculated by interpolation in the individual log concentration-effect curves. The means $( \pm$ SEM) of these logarithms are shown. The histograms on the right show the mean $( \pm S E M)$ of basal atrial rates before the addition of noradrenaline (in white columns) and the mean ( \pm SEM) of the maximal rates attained in response to the drug (shaded columns). $\left({ }^{*}\right)$ Indicates log shift statistically significant, $P<0.05$ or less. Notice that at $\mathrm{pH} 7.15$ the concentration-effect curve shifted to the right indicating that noradrenaline was less potent for increasing atrial rate than in alkalosis. $(\bullet) \mathrm{pH}: 7.65 \pm 0.01(n=14) ;(\Lambda) \mathrm{pH}: 7.15 \pm 0.01(n=12) ;\left[\mathrm{NaHCO}_{3}\right]: 24 \mathrm{mmol} / 1$

Fig. 2. Effect of "metabolic acid-base alterations" on the concentration-effect curve for chronotropic action of noradrenaline. Results were plotted as in Fig. 1. The decrease in the $\mathrm{pH}$ of the media at constant $p \mathrm{CO}_{2}$ produced a similar desensitizing effect to noradrenaline as that observed when the $p \mathrm{CO}_{2}$ was increased. (๑) pH: $7.52 \pm 0.01(n=10) ;(\Lambda) \mathrm{pH}: 7.03 \pm 0.01(n=10) ; p \mathrm{CO}_{2}: 37 \mathrm{~mm} \mathrm{Hg}$
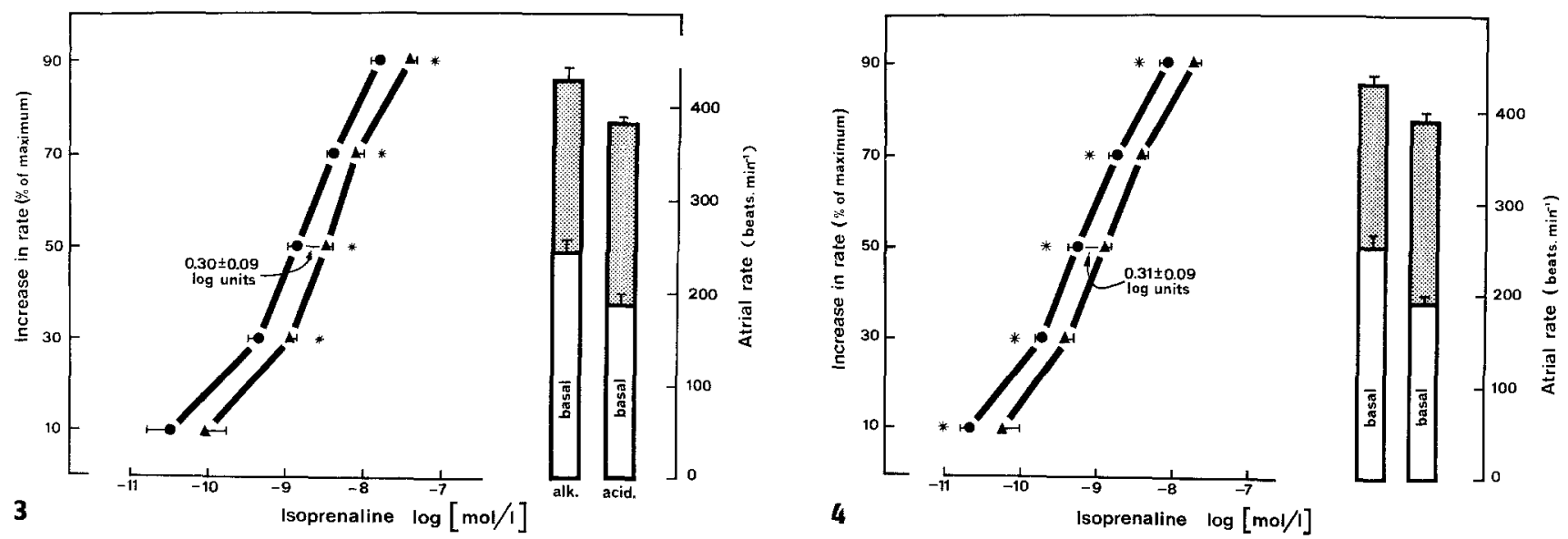

Fig. 3. Effect of the changes in $\mathrm{pH}$ on the concentration-effect curves for the chronotropic effect of isoprenaline. Results were plotted as explained in Fig. 1. Notice that the concentration-effect curve for isoprenaline was shifted to the right when the $\mathrm{pH}$ was lowered indicating a desensitizing effect of acidosis. (๑) pH: $7.61 \pm 0.01 ;(\Lambda) \mathrm{pH}: 7.03 \pm 0.01(n=8)$

Fig. 4. Effect of acid-base changes on the concentration-effect curve for isoprenaline in the presence of hydrocortisone. The inhibition of the extraneuronal uptake process did not prevent the desensitizing effect of acidosis. Results were expressed as in Fig. 1 . (•) pH: $7.65 \pm 0.01 ;(\wedge) \mathrm{pH}: 7.03$ $\pm 0.01(n=8)$

de Hurtado et al. 1979; Gende et al. 1978) and the differences detected between the concentration-effect curves determined at different $\mathrm{pH}$ values could only reflect the result from changes in basal rate. However, the effect of changes in basal rate were ruled out when results were plotted as the percentage of the maximum response. When the effects of noradrenaline were plotted as the percentage of the maximum increase in rate, an horizontal shift of the concentration-effect curves was detected (Figs. 1 and 2). Changing the $\mathrm{pH}$ from alkalosis to acidosis shifted the concentration-effect curves to the right indicating that larger concentrations of noradrenaline were require to elicit the same chronotropic effects as those obtained under alkalosis.
Similar effects of changing the $\mathrm{pH}$ of the media were observed when the chronotropic response to isoprenaline was determined under three different "respiratory" acid-base states. At low $p \mathrm{CO}_{2}(\mathrm{pH} 7.61 \pm 0.01)$ isoprenaline was more potent to increase atrial rate than at normal $\mathrm{pH}(7.44 \pm 0.01)$. On the other hand, under acidosis ( $\mathrm{pH} 7.03 \pm 0.01)$ isoprenaline was less potent to increase the rate than at $\mathrm{pH}$ 7.44. Here again only differences between concentration-effect curves determined in alkalosis and acidosis were analyzed. Figure 3 illustrates that the concentration-effect curve for isoprenaline was shifted to the right when the $\mathrm{pH}$ was decreased from 7.61 to 7.03 . The calculated mean $\log \mathrm{EC}_{50}$ were $-8.84 \pm 0.08$ at pH 7.61 and $-8.56 \pm 0.05$ at $\mathrm{pH} 7.03(n=8)(P<0.01)$. 

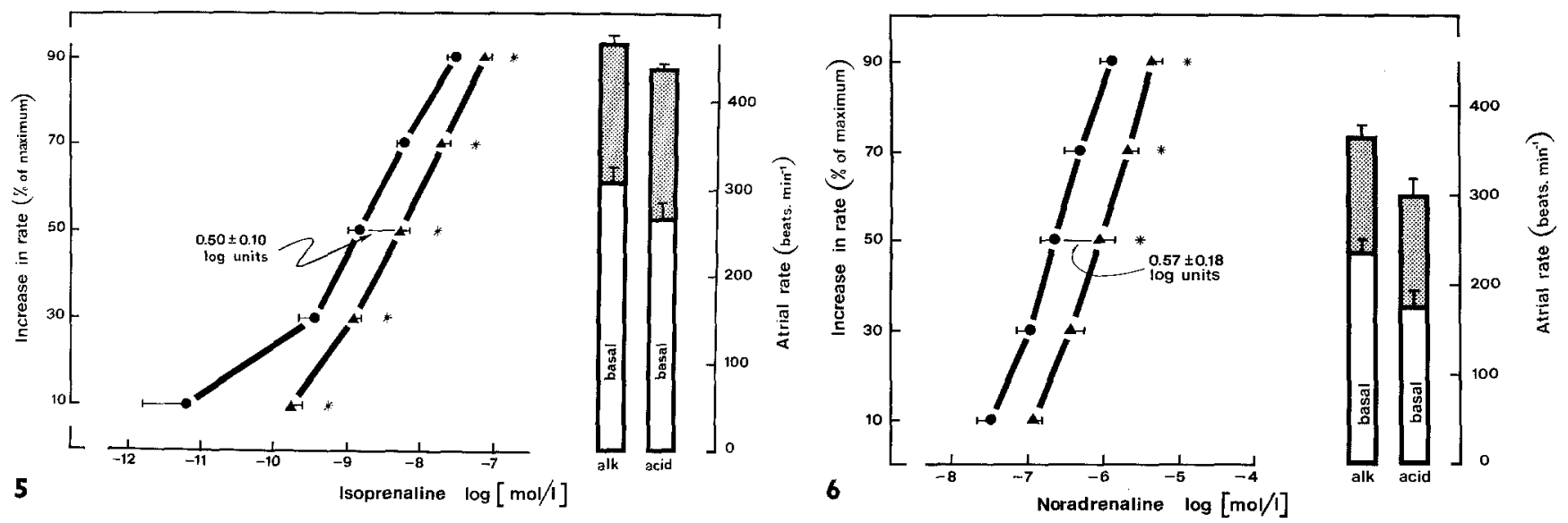

Fig. 5. Influence of the $\mathrm{pH}$ on the concentration-effect curves for isoprenaline determined in atria isolated from newborn rats. The desensitizing effect of acidosis was also detected in the atrial tissue of newborn rats. Results were plotted as in Fig. 1. (•) pH: $7.61 \pm 0.01 ;(\mathbf{\Lambda}) \mathrm{pH}: 7.06 \pm 0.01(n=7)$

Fig. 6. Effect of the $\mathrm{pH}$ on the concentration-effect curve for noradrenaline determined in atria of reserpine-pretreated rats. Concentration-effect curves were plotted as explained for Fig. 1. The depletion of noradrenaline stores did not prevent the effect of the changes in $\mathrm{pH}$ on the sensitivity to noradrenaline. $(\bullet) \mathrm{pH}: 7.84 \pm 0.02 ;(\Lambda) \mathrm{pH}: 7.03 \pm 0.03 ;\left[\mathrm{NaHCO}_{3}\right]: 24 \mathrm{mmol} / 1(n=9)$

Although the basal rate was slower in acidosis than in alkalosis the maximum increase in rate induced by isoprenaline was similar at different values of $\mathrm{pH}$.

The extraneuronal uptake process was inhibited by incubation of the atria with hydrocortisone. In control experiments the concentration-effect curve for isoprenaline shifted to the left by $0.45 \pm 0.22 \log$ units $(P<0.05)$ indicating that isoprenaline was more potent in the presence than in the absence of hydrocortisone. However, the inhibition of the extraneuronal uptake process failed to prevent the effects of the changes in $\mathrm{pH}$. Figure 4 shows that in the presence of hydrocortisone the concentration-effect curve for isoprenaline shifted horizontally to the right without changing the maximum attainable when the $\mathrm{pH}$ was decreased.

The influence of the $\mathrm{pH}$ on the sensitivity to catecholamines of atrial tissues with low content of endogenous noradrenaline was also studied. In the atria isolated from newborn rats, the noradrenaline content amounted 0.151 $\pm 0.034 \mu \mathrm{g} / \mathrm{g}(n=7)$. This value was about $17 \%$ of the noradrenaline content determined in the atria of adult animals that averaged $0.911 \pm 0.056 \mu \mathrm{g} / \mathrm{g}(n=6)^{1}$. Figure 5 illustrates that the concentration-effect curve for isoprenaline determined in the atria isolated from neonatal rats was also shifted to the right when the $\mathrm{pH}$ was decreased from 7.61 to 7.06 . Furthermore, the depletion of noradrenaline stores also failed to prevent the effect of the $\mathrm{pH}$ on the sensitivity to catecholamines. The decrease in the $\mathrm{pH}$ caused an horizontal shift to the right without changing the maximum effect of the concentration-effect curve for noradrenaline determined in atria from reserpine-pretreated rats (Fig. 6).

The influence of the $\mathrm{pH}$ on the cyclic AMP content of the isolated rat atria was measured in the absence of $\beta$-receptor stimulation and after the incubation with isoprenaline. No changes in basal cyclic AMP levels were detected between the atria submitted to stabilization at different $\mathrm{pH}$ values: 7.61 , 7.44 or 7.01 (Fig. 7). The incubation of the atria with isoprenaline up to $1 \times 10^{-9} \mathrm{~mol} / 1$, a concentration that produced marked increases in rate, did not cause any significant

1 The ratio of grams of proteins to grams of wet weight tissue was determined to be $0.129 \pm 0.005(n=5)$ in the atria of newborn rats and $0.144 \pm 0.014(n=5)$ in those atria of adult animals

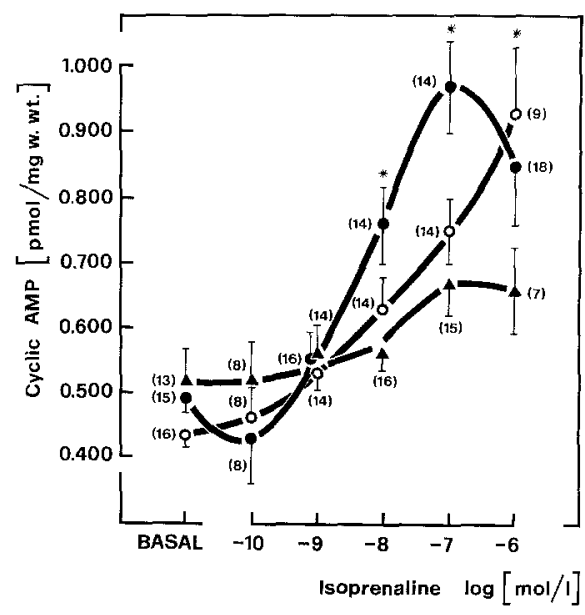

Fig. 7. Relationship between isoprenaline concentration and cyclic AMP content of the isolated rat atria incubated at different pHs of the media. Results are the mean $( \pm$ SEM) of the number of experiments indicated in parenthesis. $\left({ }^{*}\right)$ Indicates differences statistically significant $(P<0.05)$ compared to the values at $\mathrm{pH} 7.01$. Notice that the decrease in $\mathrm{pH}$ produced a progressive shift to the right of the concentration-effect curves for cyclic AMP accompanied by a reduction in the maximum response when the $\mathrm{pH}$ was lowered to 7.01 . (๑) $\mathrm{pH}: 7.61 \pm 0.01 ;(\mathrm{O}) \mathrm{pH}$ : $7.44 \pm 0.01 ;(\Lambda) \mathrm{pH}: 7.01 \pm 0.01$

change in cyclic AMP levels as it is shown in Fig. 7. The figure also illustrates that larger concentrations of the catecholamine, some of which were in excess of those required for maximal chronotropic response, produced a concentrationdependent rise of cyclic AMP above the basal levels at the three $\mathrm{pHs}$ examined. However, the rise in cyclic AMP induced by isoprenaline was greatly influenced by the $\mathrm{pH}$ of the media. The characteristic log concentration-effect curve for cyclic AMP was shifted to the right without reduction of the maximum attainable when the $\mathrm{pH}$ was lowered from 7.61 to 7.44. Thus, at $\mathrm{pH} 7.44,10$-fold larger concentrations of isoprenaline were required to produce similar increments of cyclic AMP to those obtained at $\mathrm{pH} 7.61$. When the $\mathrm{pH}$ was set at 7.01 the horizontal displacement of the curve was more accentuated. At pH 7.01, a decrease in the maximum response was also detected. The maximal effect of isoprenaline was an 
increase in cyclic AMP concentration to $0.672 \pm 0.047 \mathrm{pmol} /$ $\mathrm{mg}$ of wet weight $(n=15)$. This values was significantly smaller $(P<0.05)$ than the maximum attained either in alkalosis $(0.971 \pm 0.070 \mathrm{pmol} / \mathrm{mg}$ wet weight, $n=14)$ or at normal $\mathrm{pH}(0.928 \pm 0.103 \mathrm{pmol} / \mathrm{mg}$ wet weight, $n=9)$.

\section{Discussion}

In the isolated beating atria the alteration of the acidbase equilibrium produce two major effects, one on the spontaneous pacemaker activity (Camilión de Hurtado et al. 1979; Gende et al. 1978) and the other on the sensitivity of the atrial tissue to catecholamines. Both effects shifted the concentration-effect curves, but the influence of $\mathrm{pH}$ on the positive chronotropic effect of catecholamines was clearly detected. Under alkalosis the sensitivity of the atria for chronotropic action of noradrenaline was enhanced. Conversely subsensitivity to noradrenaline developed during acidosis. The alteration of the acid-base equilibrium at constant $p \mathrm{CO}_{2}$ produced essentially the same changes of sensitivity as those found when the $\mathrm{pH}$ was altered by changing the $p \mathrm{CO}_{2}$.

Several possibilities might be considered for explaining the influence of $\mathrm{pH}$ on the sensitivity to noradrenaline. First, the different potency of noradrenaline for increasing the rate in acidosis and alkalosis may be due to a change in the effective concentration of the amine in the vicinity of the receptors. As regards noradrenaline the effective concentration in the biophase depends at least on three factors: amount of drug administered, intra and extraneuronal inactivating process and amount of endogenous noradrenaline released. The desensitizing effect of acidosis could be atrributed to an increase of the neuronal uptake and conversely, the inhibition of this mechanism could explain the enhancement of the chronotropic potency of noradrenaline under alkalosis. If this were so, the influence of $\mathrm{pH}$ should be cancelled when an agonist which is not substrate for the neuronal uptake is used. However, the concentration-effect curve for isoprenaline was shifted to the right by acidosis. Although no experiments were performed in the presence of cocaine, the results obtained with isoprenaline, an agonist which is hardly taken up into the nerve endings (Iversen 1971), strongly suggests that the effect of the $\mathrm{pH}$ on the sensitivity to catecholamines is not mediated by alterations of the neuronal uptake.

The main metabolic disposition of isoprenaline is achieved by extraneuronal mechanisms (Callingham and Burgen 1966). Access of catecholamines to the extraneuronal metabolizing enzymes is mediated by an extraneuronal uptake process (Iversen 1965; Iversen and Langer 1969), which is inhibited by hydrocortisone (Kaumann 1972; Graefe and Trendelenburg 1974). Neither the desensitizing effect of acidosis nor the sensitizing effect of alkalosis could be ascribed to a change in the extraneuronal uptake process since inhibition of this mechanism by hydrocortisone did not prevent the shift of the concentration-effect curve for isoprenaline. Although another hydrocortisone-resistant extraneuronal uptake with low affinity for catecholamines has been described (Graefe and Trendelenburg 1974), it seems unlikely to account for the effects observed since this mechanism operates at higher catecholamines concentrations than those we used.

An alternative hypothesis for explaining the different potency of catecholamines in alkalosis and acidosis might be a noradrenaline releasing effect of alkalosis which would increase the concentration of the amine at the receptors without a real change in sensitivity. If alkalosis causes the release of noradrenaline from the nerve endings we might expect that the changes in $\mathrm{pH}$ would not affect the sensitivity to catecholamines when the content of noradrenaline in the atrial tissue is reduced. However, the sensitivity to catecholamines was enhanced by alkalosis and decreased by acidosis in the atria from reserpine-pretreated rats and also in those isolated from newborn animals.

The change in sensitivity induced by the changes in $\mathrm{pH}$ may involve an alteration in the properties of the receptors, or in some membrane characteristics or even in the intracellular mechanisms that generate the final chronotropic response.

One of the earliest intracellular events that follows catecholamine stimulation of cardiac tissue is the increment of cyclic AMP levels. The positive chronotropic effect of dibutyryl-cyclic AMP (Drummond and Hemmings 1973; Krause et al. 1970; Yamasaki et al. 1974) has been pointed out as indicating that cyclic AMP mediates the chronotropic effects of catecholamines. More recently, direct evidences have been reported by Taniguchi et al. (1977) who measured simultaneous increases in rate and in cyclic AMP content in the rabbit sinus node following the incubation with noradrenaline.

Our results, when comparing the chronotropic and cyclic AMP responses to isoprenaline, are consistent with previous results which show that the concentration-effect curve for the stimulatory effect of isoprenaline on adenyl cyclase normally lies about $2 \log$ units at the right of the curve for the chronotropic effect of isoprenaline (Birnbaumer et al. 1974). Therefore, maximal chronotropic response is elicited by isoprenaline without a complete activation of the adenyl cyclase system. In addition, maximal activation of adenyl cyclase occurs when only a small fraction of the total receptor population is occupied (Perkins 1973). All these data about the shift between the chronotropic and biochemical effects of catecholamines can explain that marked chronotropic effects can be elicited by isoprenaline without measurable changes in cyclic AMP levels. Failures to detect increases in cyclic AMP levels after incubating the atria with catecholamines in concentrations that were quite effective for increasing the rate had been also reported (Duncan and Broadley 1978; Taniguchi et al. 1977).

The concentration-effect curves for the chronotropic and cyclic AMP responses to isoprenaline were both shifted to the right when the $\mathrm{pH}$ was lowered. However, the shift of the cyclic AMP curve was greater than the shift of the chronotropic curve and therefore, similar chronotropic effects were obtained with different concentrations of cyclic AMP. Actually, in spite of the scattering of the data, they suggest a greater chronotropic effect for a given cyclic AMP concentration in acidosis. This is the reflection of the greater desensitizing effect of acidosis on the cyclic AMP response rather than on the chronotropic response. These findings are difficult to explain and several alternative hypothesis can be proposed, although only in the field of speculations: (1) acidosis potentiates or alkalosis decreases the activation of the protein kinase(s) by cyclic AMP; (2) acidosis inhibits the protein inhibitor of cyclic AMP-dependent protein kinases; (3) acidosis is followed by a subsensitivity to both the chronotropic and cyclic AMP effects of catecholamines but these effects are not causely related and (4) the chronotropic response involves a certain pool of cyclic AMP which may be 
restricted to a few sinus node cells or compartmentalized within the cardiac cells and therefore, the total cyclic AMP concentration may not always reflect the changes in this pool. Different compartmentalization of cyclic AMP and cyclic AMP-dependent protein kinase(s) have been reported in heart tissue (Corbin et al. 1977).

The actual level of intracellular cyclic AMP is determined by its rate of production via adenyl cyclase and by its rate of breakdown by cyclic nucleotide phosphodiesterases. From our results we are unable to answer the question whether the effect of acidosis is due a decrease in cyclic AMP production or to an increase in the rate of deactivation. Relevant to this are the results reported by Fredholm and Hjemdahl (1976) in the isolated rat fat cells, who measured a decrease in both the adenyl cyclase and phosphodiesterase activities in acidosis.

From the results reported here it is possible to conclude that: (1) the change in basal atrial rate that follows acid-base alterations does not correlate with changes in basal cyclic AMP levels; (2) the sensitivity of the pacemaker cells to catecholamines is reduced by acidosis, independently whether the change takes place by changing the $p \mathrm{CO}_{2}$ or by altering the bicarbonate concentration; (3) the subsensitivity to catecholamines observed when hydrogen ion activity increases can be accounted neither to the release of endogenous noradrenaline nor to alterations of the mechanisms which remove catecholamines from the biophase and (4) the fact that acidosis produced a greater subsensitivity for the catecholamine-induced increase of cyclic AMP than for the chronotropic effects, suggests that hydrogen ion probably interferes with the hormone-receptor interaction and/or with some of the pathways following $\beta$-receptor activation. It is interesting to point out that the desensitizing effect of acidosis has been also described for the chronotropic action of histamine in the rabbit atria (Hughes and Coret 1976).

Acknowledgement. The authors would like to thank Dr. Stefano for the determination of noradrenaline content in atrial tissues. This work was supported in part by the comisión de Investigaciones Cientificas, Argentina.

\section{References}

Bendixen HH, Laver MB, Flacke WB (1963) Influence of respiratory acidosis on circulatory effect of epinephrine in dogs. Circ Res $13: 64-70$

Birnbaumer L, Pohl SL, Kaumann AJ (1974) Receptors and acceptors: a necessary distinction in hormone binding studies. Adv Cyclic Nucleotide Res 4:239-281

Blinks JR (1965) Convenient apparatus for recording contractions of isolated heart muscle. J Physiol 208:537-540

Burgett GE, Visscher NB (1927) Variations of $\mathrm{pH}$ of blood and responses of vascular system to adrenaline. Am J Physiol 81:113-123

Callingham BA, Burgen ASV (1966) The uptake of isoprenaline and noradrenaline by the perfused rat heart. Mol Pharmacol 2:37-42

Camilión de Hurtado MC, Gende OA, Cingolani HE (1979) Species differences in the chronotropic response to acidbase alterations. Arch Int Physiol Biochim 87:593-602

Collip JB (1921) Reversal of depressor action of small doses of adrenaline. Am J Physiol 55:450-458

Corbin JD, Sugden PH, Lincoln TM, Keely SL (1977) Compartmentalization of adenosine $3^{\prime}: 5^{\prime}$-monophosphate and adenosine $3^{\prime}: 5^{\prime}$-monophosphate-dependent protein kinase in heart tissue. J Biol Chem 252:3854-3861

Darby T, Aldinger E, Gadsen RH, Thrower WB (1960) Effect of metabolic acidosis on ventricular isometric systolic tension and the responses to epinephrine and levarterenol. Circ Res 8:1242-1253

Downing SE, Talner NS, Gadner RH (1965) Cardiovascular responses to metabolic acidosis. Am J Physiol 208:237-242
Drummond GI, Hemmings SJ (1973) Inotropic and chronotropic effects of dibutyryl cyclic AMP. Adv Cyclic Nucleotide Res 1:307-316

Duncan C, Broadley KJ (1978) Correlation between cAMP production in guinea-pig left and right atria and their inotropic and chronotropic response to orciprenaline at different temperatures. Mol Pharmacol 14:1063-1072

Fredholm BB, Hjemdahl P (1976) Inhibition by acidosis of adenosine $3^{\prime} 5^{\prime}$ cyclic monophosphate accumulation and lypolisis in isolated rat fat cells. Acta Physiol Scand 96:160-169

Gende OA, Camilión de Hurtado MC, Cingolani HE (1978) Chronotropic responses of isolated atria to acid-base alterations. Arch Int Physiol Biochim 86:997-1010

Graefe KH, Trendelenburg U (1974) The effect of hydrocortisone on the sensitivity of the isolated nictitating membrane to catecholamines: relationship to extraneuronal uptake and metabolism. NaunynSchmiedeberg's Arch Pharmacol 286:1-48

Häggendal J (1963) An improved method for fluorometric determination of small amounts of adrenaline and noradrenaline in plasma and tissues. Acta Physiol Scand 59:242-254

Harper JF, Brooker G (1975) Fentomole sensitive radioimmuno assay for cyclic AMP and cyclic GMP after $2^{\prime} 0^{\prime}$ acetylation by acetic anhydride in aqueous solution. J Cyclic Nucleotide Res $1: 207-218$

Hughes MJ, Coret IA (1976) The effect of $\mathrm{pH}$ on rabbit atrial response to histamine. Can J Physiol Pharmacol 54:118-127

Iversen LL (1965) The uptake of catecholamine at high perfusion concentration in the isolated rat heart: a novel catecholamine uptake process. Br J Pharmacol 25:18-33

Iversen LL (1971) Role of transmitter uptake mechanism in synaptic neurotransmission. Br J Pharmacol 41:571-591

Iversen LL, Langer SZ (1969) Effects of phenoxibenzamine on the uptake and metabolism of noradrenaline in the rat heart and vas deferens. Br J Pharmacol 37:627-637

Kaumann AJ (1972) Potentiation of the effects of isoprenaline and noradrenaline by hydrocortisone in the cat heart muscle. NaunynSchmiedeberg's Arch Pharmacol 273:134-153

Krause EG, Halle W, Kallabis E, Wollenberger A (1970) Positive chronotropic response of cultured isolated rat heart cells to $N^{6}, 2^{\prime}-0$ dibutyryl-3':5'-adenosine monophosphate. J Mol Cell Cardiol $1: 1-10$

Manley ES, Woodbury RA, Nash CL (1966) Cardiovascular responses to epinephrine during acute hipercapnia in dogs: effect of automatic blocking drugs. Circ Res 18:573-584

Nahas GG, Poyart C(1967) Effect of arterial $\mathrm{pH}$ alterations on metabolic activity of norepinephrine. Am J Physiol 212:765-772

Page IH, Olmstead F (1951) Influence of respiratory gas-mixtures on arterial pressure and vascular reactivity in normal and hypertensive dogs. Circ Res 3:801-819

Perkins JP (1973) Adeny1 Cyclase. Adv Cyclic Nucleotide Res 3:1-64

Salant W, Johnston RL (1924) Responses of isolated frog heart to changes in hydrogen ion concentration and adrenaline. J Pharmacol Exp Ther 23:373-383

Schroeder JS, Robison SC, Miller HA, Harrison DC (1970) Effects of respiratory acidosis on circulatory response to isoproterenol. Am J Physiol 218:448-452

Steiner AL, Parker ChW, Kipnis DM (1972) Radioimmuno assay for cyclic nucleotides. I. Preparations of antibodies and iodinated cyclic nucleotides. J Biol Chem 247:1106-1113

Taniguchi T, Fujiwara M, Ohsumi K (1977) Positive involvement of cyclic adenosine $3^{\prime} 5^{\prime}$ monophosphate in the genesis of catecholamines-induced tachycardia in isolated rabbit sinoatrial node. $\mathrm{J}$ Pharmacol Exp Ther 201:678-688

Tenney SM (1956) Sympatho-adrenal stimulation by carbon dioxide and the inhibitory effect of carbonic acid on epinephrine response. Am J Physiol 187:341-346

Yamasaki Y, Fujiwara M, Toda N (1974) Effects of intracellularly applied $3^{\prime} 5^{\prime}$ adenosine monophosphate and dibutyril cyclic $3^{\prime} 5^{\prime}$ adenosine monophosphate on the electrical activity of sinoatrial nodal cells of the rabbit. J Pharmacol Exp Ther 190:15-20

Received October 13, 1980/Accepted June 23, 1981 